\title{
IMPLANTAÇÃO DE MEDIDAS DE HIGIENE NA ORDENHA PARA MELHORIA DA QUALIDADE DO LEITE NO MUNICÍPIO DE PATY DO ALFERES/RJ, BRASIL
}

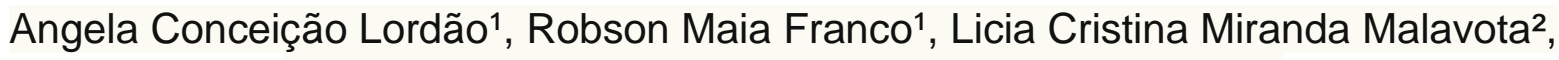 \\ Sergio Borges Mano'1, Marco Antonio Sloboda Cortêz ${ }^{1}$ \\ 1 UFF \\ 2 UFRRJ \\ Correspondência: Angela Conceição Lordão: angelalordao@veterinaria.med.br
}

RESUMO: A qualidade do leite é um tema em constante discussão no Brasil, e em 2011 foi publicada a Instrução Normativa 62, do Ministério da Agricultura, Pecuária e Abastecimento (MAPA) na qual são estabelecidos critérios e padrões para a produção do leite cru, alterando a Instrução Normativa 51 de 2002. A obtenção do leite de forma higiênica é fundamental para a qualidade do produto final e depende do primeiro elo da cadeia do leite, composto principalmente por pequenas propriedades de base familiar. Considerando a importância do leite na alimentação, e a necessidade de melhoria da qualidade do leite no país, objetivou-se no presente trabalho avaliar a eficiência da implantação das boas práticas agropecuárias na produção leiteira entre agricultores familiares, no município de Paty do Alferes, Rio de Janeiro. Amostras foram coletadas para verificação do atendimento à legislação vigente e um curso teórico e prático sobre ordenha higiênica e qualidade do leite foi desenvolvido, com a participação de 11 famílias. As análises realizadas foram: contagem de bactérias heterotróficas aeróbias mesófilas (CBHAM), contagem de bactérias heterotróficas aeróbias psicrotróficas, contagem de células somáticas (CCS), composição (Extrato Seco Desengordurado - ESD, gordura e proteína), acidez, densidade e crioscopia. Nos resultados encontrados após capacitação, observou-se melhoria dos parâmetros analisados: $100 \%$ dos produtores em conformidade para densidade e crioscopia; $81,82 \%$ para acidez; $90,9 \%$ em relação à CCS e $63,64 \%$ para CBHAM; $100 \%$ para gordura, $81,82 \%$ para ESD e $63,64 \%$ para proteína. Podese concluir que se faz necessário um acompanhamento contínuo das propriedades para que os produtores, em sua totalidade, consigam se adequar aos critérios exigidos pela legislação.

Palavras-chave: agricultura familiar; higiene; Instrução Normativa 62; ordenha

\section{IMPLEMENTATION OF MILKING HYGIENE MEASURES FOR IMPROVING THE QUALITY OF MILK IN THE CITY OF PATY DO ALFERES / RJ, BRAZIL}

\begin{abstract}
Milk quality is a constantly discussion theme in Brazil, and in 2011 the Normative Instruction 62 of Brazilian Ministry of Agriculture was publicated, establishing criteria and patterns for raw milk production. Getting milking in a hygienic way is critical to guarantee the quality of the final product, and depends at first link of the milk chain, composed mainly by family-based small farms. Considering the importance of milk in human diet and the necessity to improve the milk quality in the country, the aim of this project was to develop the technical knowledge of milk producers in Paty do Alferes District, Rio de Janeiro. Samples were collected to check if they follow the current legislation and a theoretical and practical course about hygienic milking was applied for 11 families. After that, new analyses were done to evaluate if the practices taught were being used, and if in fact there were improvements in milk quality. The following analyses were done: bacterial (heterotrophic aerobic mesophilic and psychotrophic count), somatic cells counting, composition (non fat solids, fat and protein), acidity, density and cryoscopy. According to the results, an improvement of the analyzed parameters were observed after training, in which $100 \%$ of producers were in accordance with legislation in density and cryoscopy analysis, $81,82 \%$ in acidity, $90,91 \%$ in somatic cells counting and $63,64 \%$ in bacterial heterotrophic aerobic mesophilic counts. In composition, $100 \%$ of the samples were in accordance in fat analysis, $81,82 \%$ in total solids and $63,64 \%$ in protein. Thus, continuous monitoring of the farms is necessary to get all producers in accordance to the legislation criteria and avoid their exclusion of milking activities.
\end{abstract}

Key Words: familiar agriculture; hygiene; milking, Normative Instruction 62 
Implantação de medidas de higiene na ordenha para melhoria da qualidade do leite no município de Paty do Alferes/RJ, Brasil

\section{INTRODUÇÃO}

A atividade leiteira é adotada pelos produtores familiares principalmente pela garantia da renda mensal, essencial para a unidade familiar, e pelo baixo risco da atividade (Salvestro et al., 2009). A agricultura familiar representa no Brasil $84,4 \%$ dos estabelecimentos, e é responsável por $58 \%$ da produção de leite no país (MDA, 2012).

No Brasil, a qualidade do leite vem sendo bastante discutida, com foco principal na qualidade da matéria-prima, controle do processo e manutenção da qualidade, com o intuito de implementar melhorias em toda a cadeia láctea (Lima et al., 2006).

No processo de obtenção do leite, a ordenha constitui a etapa de maior vulnerabilidade para a ocorrência de contaminações por sujidades, microrganismos e substâncias químicas que podem ser imediatamente incorporados ao produto in natura (Costa, 2006). Sendo assim, os procedimentos adotados durante esta etapa são determinantes para a qualidade final do produto (Silva et al., 2011).

A temperatura de armazenamento do leite, bem como o período em que é armazenado, determinam de forma pronunciada a intensidade da multiplicação de espécies microbianas. Temperaturas baixas inibem ou reduzem a multiplicação de bactérias e a atividade de enzimas degradativas (Arcuri et al., 2006).

Somente 0 resfriamento não assegura a qualidade microbiológica do leite, pois a carga bacteriana inicial possui grande importância no resultado final da contagem bacteriana. Se a contaminação inicial é muito alta, após 24 ou 48 horas de estocagem do leite a 4ํㅡ, será difícil obter um produto com pequena população bacteriana, mesmo que o resfriamento seja feito logo após a ordenha. Isso também depende das características da microbiota presente no leite, principalmente os microrganismos psicrotróficos (Brito, 2010).

Quando comparados aos custos no processamento da matéria-prima, o leite com baixa qualidade gera custos adicionais à produção de produtos lácteos. Ocorre queda no rendimento de derivados, dificuldades no processamento, com paradas adicionais para limpeza de incrustações nos equipamentos e perda de produto final, além de impossibilitar a fabricação de produtos de maior valor agregado (Barros et al., 2001; Sousa et al., 2012).

Para alcançar os padrões determinados pela legislação, é necessário muito mais que inspeção e vigilância, mas a disseminação de uma política de qualidade envolvendo todos os participantes do processo. As mudanças em prol da qualidade exigem a consciência e aculturamento da indústria e do produtor (Viana et al., 2010). Um grande desafio é encontrar linguagem e incentivo corretos para mostrar ao pequeno proprietário seu papel nesta economia, de forma a adequar o discurso técnico à prática da agricultura familiar como atividade profissional com o devido planejamento, metas e resultados (Silva et al., 2010).

A qualidade do leite (matériaprima) pode ser avaliada através de análises físico-químicas, como o teor em proteínas e gordura, que afetam diretamente o rendimento industrial dos derivados lácteos; e análises microbiológicas, como a contagem de bactérias heterotróficas, aeróbias e mesófilas (CBHAM), a contagem de células somáticas (CCS) e a contagem de bactérias heterotróficas, aeróbias e psicrotróficas (CBHAP), que afetam negativamente o processo e a qualidade do produto final (Andrade et al., 2009; Sousa et al., 2012), como também diminuem a validade comercial (Millogo et al., 2010). 
Dessa forma, objetivou-se no presente estudo avaliar a importância do aprimoramento de conhecimentos técnicos na produção de leite para melhoria da qualidade do leite cru produzido em propriedades de cunho familiar.

\section{MATERIAL E MÉTODOS}

Foi realizado inicialmente um questionário em propriedades rurais situadas no município de Paty do Alferes, RJ, que objetivou principalmente determinar os procedimentos realizados na propriedade antes, durante e após a obtenção do leite, relacionadas à qualidade da matéria-prima, utilizando como parâmetro os padrões da Instrução Normativa 51 do Ministério da Agricultura, Pecuária e Abastecimento (Brasil, 2002), alterada pela Instrução Normativa 62 no fim do ano de 2011. O questionário abordou principalmente informações relativas à higiene durante a ordenha, armazenamento e transporte do leite; sanidade animal; fatores de produção e gestão e aspectos da propriedade e instalações. De posse dessas informações foi possível traçar o perfil dos produtores, e os principais problemas que interferem na qualidade do leite nessas propriedades.

Foram coletadas amostras de leite de 11 propriedades, para análises laboratoriais físico-químicas e microbiológicas, que fornecessem maiores informações no que diz respeito à qualidade do leite produzido.

Após a realização das análises laboratoriais e estudo dos dados levantados nas entrevistas, foi então elaborado um curso de qualidade do leite, com a participação de 11 produtores, para capacitação em práticas de higiene na produção de leite. O curso aconteceu em dois dias (16 horas), na propriedade rural de um dos produtores participantes, sendo teórico- prático. Os temas abordados no curso foram: 1) Importância nutricional do leite; 2) A agricultura familiar na produção de leite; 2) Qualidade do leite; 3) IN 51 (alterada pela IN 62) e seus padrões; 4) Importância da ordenha higiênica; 5) Influência da temperatura no armazenamento do leite cru e 6) Mastite: formas de prevenção e controle da doença. $\mathrm{Na}$ prática, os produtores aprenderam a rotina básica de ordenha realizada de forma higiênica, e os testes para detecção e prevenção da mastite. Os produtores foram acompanhados individualmente após o curso, para melhor fixação do conhecimento adquirido, e novamente amostras do leite cru foram coletadas a fim de observar melhoria ou não da qualidade do leite em função do aprendizado.

Foram coletadas amostras de leite cru em frascos estéreis de aproximadamente $50 \mathrm{~mL}$, contendo um comprimido de Bronopol $\AA$, ou Azidiol $\AA$, em propriedades leiteiras do município de Paty do Alferes - RJ. As amostras foram homogeneizadas para ação correta do conservante, acondicionadas em caixas isotérmicas contendo gelo reciclável, e transportadas ao Laboratório de Qualidade do Leite da Embrapa Gado de Leite, de Juiz de Fora - MG, integrante da Rede Brasileira de Laboratórios de Controle da Qualidade do Leite (RBQL). As amostras contendo Bronopol $\AA$ foram analisadas pela metodologia de Espectrometria de Absorção no Infravermelho Médio, que forneceu resultados de gordura, lactose, extrato seco total (EST), extrato seco desengordurado (ESD) e proteína. Além da análise de composição centesimal, as mesmas amostras foram submetidas à metodologia de citometria de fluxo, para a contagem de células somáticas (CCS). As amostras contendo o comprimido de Azidiol ${ }^{\circledR}$ foram analisadas pela metodologia de citometria de fluxo, para a contagem de unidades formadoras de colônias (UFC). 

município de Paty do Alferes/RJ, Brasil

Análises de acidez titulável e densidade foram realizadas no momento da coleta das amostras.

Amostras de leite sem conservantes, com aproximadamente 80 $\mathrm{mL}$, foram também identificadas, acondicionadas em caixas isotérmicas com gelo reciclável, e então transportadas imediatamente ao Laboratório de Tecnologia e Inspeção de Leite e Derivados, da Universidade Federal Fluminense (UFF) para a determinação do índice Crioscópico, utilizando crioscópio eletrônico. As análises foram realizadas em triplicata, utilizando-se como valor final a média dos três resultados. Além das amostras contendo conservantes, também foram coletadas amostras em recipientes esterilizados para contagem de bactérias heterotróficas, aeróbias psicrotróficas no Laboratório de Controle Microbiológico de Produtos de Origem Animal da UFF. Para tal análise, foram utilizados $25 \mathrm{~mL}$ de cada amostra de leite adicionado de $225 \mathrm{~mL}$ de solução salina peptonada tamponada a $0,1 \%$, que foram homogeneizados no equipamento "Stomacher", obtendo-se assim a diluição $10^{-1}$. A partir desta diluição foram transferidas alíquotas de $100 \mu \mathrm{L}$ diluídas em "eppendorfs" com $900 \mu \mathrm{L}$ de solução salina peptonada a $0,1 \%$, caracterizando assim a diluição $10^{-2}$ e procedendo-se da mesma forma, para obtenção da diluição $10^{-3}$ e demais diluições. Foi adotada a metodologia de plaqueamento em profundidade, baseando-se na Instrução Normativa no 62 de 26 de agosto de 2003 (BRASIL, 2003) do Ministério da Agricultura, Pecuária e Abastecimento (MAPA), que oficializa os métodos analíticos oficiais para análises microbiológicas para controle de produtos de origem animal e água. $\mathrm{O}$ meio de cultura utilizado foi o "Plate Count Agar" (PCA) da marca Merck (Cat. № 1.05463.0500/5007).

Os resultados foram obtidos através das médias dos resultados das repetições e expressos em log UFC/mL da amostra. A incubação foi efetuada a temperatura de $7^{\circ} \mathrm{C}$, pelo período de dez dias. Os dados foram submetidos a análises estatísticas utilizando-se 0 software GraphPad Prism v5 - 2007. Foi utilizado o teste $t$ de Student a $5 \%$ de significância para avaliar a diferença entre as médias das análises do antes e depois da capacitação em técnicas de obtenção higiênica e qualidade do leite.

\section{RESULTADOS E DISCUSSÃO}

Em relação ao teste de acidez, houve um aumento no número de produtores em conformidade com a legislação, passando de $54,55 \%$ para $81,82 \%$ após o curso. De acordo com Fonseca e Santos (2000), esses resultados significariam melhoria na qualidade microbiológica do leite cru, de um maior número de produtores, pois o teste de acidez titulável detecta aumentos na concentração de ácido lático formado pela fermentação da lactose por bactérias mesófilas.

No teste de densidade, inicialmente $63,64 \%$ dos produtores estavam conformes, porém nas análises posteriores ao curso e assistência técnica fornecidos, $100 \%$ dos produtores encontravam-se dentro dos padrões da legislação. Esses resultados descartam fraudes como a adição de água, ou a retirada de gordura, que diminui ou aumenta a densidade, respectivamente, conforme esclarecem Fonseca e Santos (2000).

Nos resultados da análise de depressão do ponto de congelamento ou crioscopia, observou-se um aumento de $90,91 \%$ para $100 \%$ de produtores em conformidade com a legislação. Mais uma vez pôde-se observar a ausência de fraude por aguagem do leite, pois segundo Castanheira (2010), a temperatura de congelamento do leite é mais baixa que a da água, sendo a 
crioscopia um método útil para avaliação de fraude por adição de água.

A redução, ou até mesmo ausência de não conformidades observadas na segunda coleta de amostras, demonstra que houve implementação das práticas ensinadas nas propriedades rurais do Município de Paty do Alferes. Mendes et al. (2010), em pesquisa com 32 amostras de leite cru informal, encontraram $50 \%$ das amostras na análise de crioscopia em desacordo com a legislação, 18,8\% na análise de densidade e 6,2\% em relação à acidez.

Os resultados para as análises de acidez, densidade e crioscopia não apresentaram diferença significativa $(P<0,05)$ entre as médias das primeiras $\mathrm{e}$ últimas análises, pelo teste $\mathrm{t}$ de Student. As médias foram 0,18 antes e depois para acidez, 1,030 antes e depois para densidade, $-0,5488^{\circ} \mathrm{H}$ e $0,5420^{\circ} \mathrm{H}$ antes e depois, respectivamente para crioscopia.

Os resultados encontrados no presente trabalho sugerem melhoria considerável das práticas de prevenção e controle da mastite no rebanho, com elevado aumento de produtores em conformidade com a legislação, em relação à CCS. De acordo com os padrões em vigência $\left(6,5 \times 10^{5}\right.$ células $/ \mathrm{mL}$ ), como determina a IN 62 (Brasil, 2011), 90,91\% dos produtores que participaram do estudo estavam em conformidade após a capacitação, porcentagem que inicialmente era de $54,55 \%$. Se os prazos para diminuição dos limites de CCS não fossem alterados pela IN 62, os limites seriam de $4 \times 10^{5}$ células $/ \mathrm{mL}$ pela IN 51 (Brasil, 2002), e a porcentagem de produtores em conformidade diminuiria para $18,18 \%$ antes do curso, e $72,73 \%$ após a capacitação. A partir da IN 62, os valores para CCS passarão a $5 \times 10^{5}$ a partir de 2014 , e $4 \times 10^{5}$ apenas a partir de 01/07/2016, nas regiões Sul, Sudeste e Centro-Oeste. Lima et al. (2006), encontraram resultados semelhantes em 13 propriedades rurais na região agreste de Pernambuco, com 84,6\% das propriedades apresentando-se dentro dos padrões da IN $51\left(7,5 \times 10^{5}\right.$ células $/ \mathrm{mL}$ ). Com contagem menor que $4 \times 10^{5}$ células $/ \mathrm{mL}, \quad 0$ número de propriedades diminuiu para 53,84\%, valor inferior ao encontrado no presente estudo após a capacitação dos produtores, o que enfatiza a importância do aprimoramento dos conhecimentos dos produtores na produção de leite, bem como o acompanhamento das propriedades. Entretanto, Souto et al. (2009) encontraram $91,67 \%$ de 36 amostras de leite de produtores do Estado de São Paulo dentro dos limites de $4 \times 10^{5}$ células $/ \mathrm{mL}$, estando apenas três produtores $(8,33 \%)$ fora desse limite para CCS.

Fernandes et al. (2003), explicita que considerando o rendimento médio de $1 \mathrm{Kg}$ de queijo para $10 \mathrm{~L}$ de leite, ocorre perda de $500 \mathrm{Kg}$ de queijo para cada $100.000 \mathrm{~L}$ de leite processado com alta CCS. Este fato foi corroborado por Bueno et al. (2005), que concluíram em seu estudo no Estado de Goiás, que o aumento da CCS interferia na composição do leite, estando relacionada à redução das concentrações de proteína, lactose e sólidos totais.

A média de CCS encontrada no presente estudo foi de 820.818,18 células $/ \mathrm{mL}$ de leite inicialmente, e 294.272,73 células/mL de leite após a introdução de técnicas de higiene nas propriedades. O alto valor da média obtida inicialmente neste estudo está de acordo com as médias encontradas por Lira (2007) nos Estados de Pernambuco (611.659), Paraíba (975.281) e Rio Grande do Norte (955.892). As médias entre as primeiras e as últimas análises do presente estudo apresentaram diferença significativa $(P<0,05)$, pelo teste t de Student. 

município de Paty do Alferes/RJ, Brasil

Em relação à CBHAM os valores encontrados no presente estudo, foram altos. Mesmo após a capacitação dos produtores, apesar da diminuição considerável no valor da média, muitas amostras ainda continuaram em não conformidade com a legislação. Inicialmente $36,36 \%$ estavam em conformidade com os padrões atuais para CBHAM $\left(6,5 \times 10^{5} \mathrm{UFC} / \mathrm{mL}\right)$, valor que quase dobrou após a capacitação dos produtores, passando para $63,64 \%$. Porém, ao se avaliar o limite de $10^{5}$ UFC/mL que estaria em vigor pela IN 51 desde 01/07/2011 (Brasil, 2002), os valores deixaram muito a desejar, pois nenhum dos produtores inicialmente se enquadrava, e apenas $27,27 \%$ se adequaram após a capacitação. A partir da IN 62 (Brasil, 2011), o limite de $10^{5}$ passará a vigorar somente a partir de 01/07/2016 nas regiões Sul, Sudeste e Centro-Oeste, dando mais tempo aos produtores para se adequarem. Apesar disso, a média para a CBHAM diminuiu consideravelmente na última análise, caindo de 2.282.636,36 para menos da metade $(988.818,18)$.

Vários outros pesquisadores encontraram elevados níveis de contaminação por bactérias aeróbias mesófilas (Arcuri et al., 2008; Nero et al., 2005), indicando falhas de práticas de higiene, conservação e refrigeração do leite nas propriedades, evidenciando a grande importância de programas de educação continuada para a melhoria da qualidade do leite. Souto et al. (2009), analisando 36 amostras de leite cru no Estado de São Paulo, encontraram $15(41,67 \%)$ atendendo aos requisitos de $10^{5} \mathrm{UFC} / \mathrm{mL}$, e 21 $(58,33 \%)$ acima deste limite, contudo Arcuri et al. (2006) encontraram resultados semelhantes, com 11 $(45,83 \%)$ de 24 propriedades dentro dos padrões para CBT. Esses resultados, apesar de melhores que o encontrado no presente trabalho $(27,27 \%)$, ainda são insatisfatórios, sendo necessária maior atenção em relação à contaminação microbiológica nas propriedades, com a implantação de medidas imediatas para a melhoria da qualidade do leite cru, visando o atendimento dos requisitos da IN 62 (Brasil, 2011). O resfriamento da matéria-prima nas propriedades e o transporte do leite a granel em caminhões isotérmicos, também são medidas importantes a serem tomadas visando a inibição da multiplicação bacteriana e consequente melhoria da qualidade do leite, e constam na IN 62 (Brasil, 2011).

As médias para CBHAM entre as primeiras e as últimas análises, apresentaram diferença significativa $(P<0,05)$, pelo teste t de Student.

Foram verificadas no presente trabalho altas contagens de bactérias psicrotróficas no leite cru. Apesar de não existir regulamentação específica quanto aos microrganismos psicrotróficos em leite cru destinado à fabricação de produtos lácteos, é imprudente a fabricação de produtos a partir do leite cru com população de psicrotróficos superior a 5,0 x $10^{6}$ UFC/mL (PINTO et al., 2006). Neste trabalho, o leite de nenhum produtor estava dentro desse limite inicialmente, e oito $(72,73 \%)$ se enquadraram nesses valores após a introdução das práticas ensinadas nas propriedades. Santos et al. (2009), citam que a redução do rendimento na fabricação de queijos, ocorre quando as contagens de psicrotróficos no leite cru excedem $10^{6}$ $\mathrm{UFC} / \mathrm{mL}$ de leite, portanto inicialmente nenhuma das amostras atenderam a esse limite, e quatro (36,36\%) amostras posteriormente estavam com valores inferiores a $10^{6} \mathrm{UFC} / \mathrm{mL}$.

$\begin{array}{llr}\text { Em Brasil } & (2008) \text { há a } \\ \text { determinação do controle da } & \text { dantaminação } & \text { microbiota }\end{array}$ psicrotrófica de tal forma que sua contagem não exceda a $10 \%$ do número total de aeróbios mesófilos, o que 
ocorreu apenas em uma $(9,09 \%)$ das amostras analisadas neste trabalho, mesmo após o curso de capacitação. Os altos valores encontrados na contagem de bactérias psicrotróficas são associados por Arcuri et al. (2008) à falhas nas condições de higiene na propriedade ou ainda no tempo e temperatura de estocagem.

Em relação à gordura, 100\% das amostras apresentavam-se dentro dos padrões tanto antes, quanto após a capacitação, porém Almeida et al. (1999), encontraram situação diferente na cidade de Alfenas-MG, onde de 21 amostras coletadas de leite cru, $71,43 \%$ encontravam-se com porcentagem de gordura inferior à $3 \%$.

A porcentagem de amostras em conformidade em relação à quantidade de proteína era de $81,82 \%$ e caiu para $63,64 \%$ após a capacitação. Este resultado é semelhante ao encontrado por Lira (2007) nos Estados da Paraíba, Pernambuco e Rio Grande do Norte, onde $64,90 \%$ das amostras encontravam-se em conformidade em relação à quantidade de proteína preconizada pela IN 62 (Brasil, 2011). Segundo o mesmo autor, devem ser levados em consideração os diferentes manejos alimentares ou condições ambientais, que influenciam o teor de proteína, assim como o mês do ano. No presente trabalho, as últimas amostras foram coletadas nos meses de seca, período de baixa disponibilidade de alimento, o que pode ter influenciado na queda da porcentagem de produtores em conformidade em relação à quantidade de proteína do leite.

Em relação ao ESD, a mesma porcentagem de produtores em conformidade com a legislação em vigor foi mantida, antes e após a capacitação dos produtores.

As médias dos resultados para as análises de composição do leite cru, antes e após da capacitação, não apresentaram diferença significativa $(P<0,05)$, pelo teste t de Student.

\section{CONCLUSÃO}

Os resultados encontrados no presente estudo, a partir dos questionários aplicados e análises iniciais, permitiram concluir que muitos produtores desconhecem as exigências da IN 62 (Brasil, 2011), e não aplicam medidas de higiene na ordenha para a obtenção e a manutenção de um leite de qualidade. A redução das não conformidades nas últimas análises realizadas comprova a necessidade e eficácia de acompanhamento das propriedades leiteiras e realização de capacitações para produtores rurais na produção de leite, pelos órgãos oficiais de assistência técnica e extensão rural. Dessa forma, os trabalhos de acompanhamento das propriedades rurais e análises da matéria-prima devem continuar para que todos os produtores possam se adequar aos padrões exigidos pela legislação e não sejam eliminados da produção leiteira, ocasionando problemas sociais, como o êxodo rural, e econômico, com a redução da produção de leite no país.

\section{REFERÊNCIAS}

ALMEIDA, A.C.; SILVA, G.L.M.; SILVA, D.B. et al. Características físico-químicas e microbiológicas do leite cru consumido na Cidade de Alfenas, MG. Revista Universidade Alfenas, v.5, p.165-168, 1999.

ANDRADE, U.V.C.; HARTMANN, W.;

MASSON, M.L. Isolamento microbiologico, contagem de células somáticas e contagem bacteriana total em amostras de leite. ARS Veterinaria, v.25, n.3, p.129-135, 2009.

ARCURI, E.F., BRITO, M.A.V.P.; BRITO, J.F.R. et al. Qualidade microbiológica do leite refrigerado nas fazendas. Arquivo Brasileiro de Medicina Veterinária e Zootecnia, v.58, n.3, p.440-446, 2006.

ARCURI, E.F.; SILVA, P.D.L.; BRITO, M.A.V.P., et al. Contagem, isolamento e caracterização de bactérias psicrotróficas contaminantes de leite 

municipio de Paty do Alferes/RJ, Brasil

cru refrigerado. Ciência Rural, v.38, n.8, p.2250-2255, 2008.

BARROS, G. S. A. C.; GALAN, V. B.; GUIMARÃES, V. A. et al. Sistema Agroindustrial do leite no Brasil. Brasília: Embrapa Informação Tecnológica, 2001. 170p.

BRASIL. Ministério da Agricultura, Pecuária e Abastecimento. Regulamento da Inspeção Industrial e Sanitária de Produtos de Origem Animal - RIISPOA. Brasília: 2008. 241 p.

BRASIL. Ministério da Agricultura, Pecuária e Abastecimento. Instrução Normativa no 51, de 18 de setembro de 2002. Aprova e oficializa o Regulamento técnico de identidade e qualidade de leite cru e refrigerado. Disponível em: <http: //anfip.datalegis.inf.br/view/txato.php?TIPO=IN M\&NUMERO $=00000051 \&$ SEQ $=000 \& A N O=200$ 2\&ORGAO=MAA\&TIPITEM $=X \& D E S I T E M=4 \& D$ $E S I T E M F I M=>$. Acesso em: 1 set 2010.

Instrução Normativa nํ 62, de

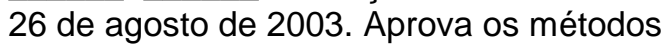
analíticos oficiais para análises microbiológicas para controle de produtos de origem animal e água. Diário Oficial [da] República Federativa do Brasil, Brasília, DF, p.14, 18 set. 2003, Seção 1, 2003.

Instrução Normativa nำ 62, de 29 de dezembro de 2011. Aprova o

Regulamento Técnico de Produção, Identidade e Qualidade do Leite tipo A, o Regulamento Técnico de Identidade e Qualidade de Leite Cru Refrigerado, o Regulamento Técnico de Identidade e Qualidade de Leite Pasteurizado e o Regulamento Técnico da Coleta de Leite Cru Refrigerado e seu Transporte a Granel, em conformidade com os Anexos desta Instrução Normativa.. Disponível

em:<http://sistemasweb.agricultura.gov.br/sisleg is/action/detalhaAto.do?method=consultarLegisl acaoFederal>. Acesso em: 10 ago 2013.

BRITO, J.R.F. Pagamento do leite por qualidade: Uma visão do produtor. In:

Estratégias e conhecimentos para 0 fortalecimento do agronegócio do leite. Cap. I. Embrapa Gado de Leite, Juiz de Fora - MG. 2010. 280p.

BUENO,V.F.F.; MESQUITA, A.J.; NICOLAU, E.S. et al. Contagem celular somática: relação com a composição centesimal do leite e período do ano no Estado de Goiás. Ciência Rural, v.35, n.4, 2005.

CASTANHEIRA, A.C.G. Manual básico de controle de qualidade de leite e derivados. São Paulo: Cap-Lab, 2010. 269p.
COSTA, F.F. Interferência de práticas de manejo na qualidade microbiológica do leite produzido em propriedades rurais familiares. Jaboticabal, 2006. 64f. Dissertação (Mestrado em Produção Animal) - Faculdade de Ciências Agrárias, Universidade Estadual Paulista "Julio de Mesquita Filho", Jaboticabal. 2006.

FERNANDES, A.M.; MULLER, M.D.; CARVALHO, G.R. Avaliação do iogurte produzido com leite contendo diferentes níveis de células somáticas. Pirassununga, 2003. 87 f. Dissertação (Mestrado em Zootecnia) - Faculdade de Zootecnia e Engenharia de Alimentos, Universidade Estadual de São Paulo, Pirassununga, 2003.

FONSECA, L. F. L.; SANTOS, M. V. Qualidade do leite e controle da mastite. São Paulo: Lemos Editorial, 2000. 175 p.

LIMA, M.C.G.; SENA, M.J.; MOTA, R.A. et al. Contagem de células somáticas e análises físico-químicas e microbiológicas do leite cru tipo c produzido na região agreste do estado de Pernambuco. Arquivo do Instituto de Biologia, v.73, n.1, p.89-95, 2006.

LIRA, A.V. Contagem de células somáticas e composição do leite cru resfriado nos estados da Paraíba, Pernambuco e Rio Grande do Norte. Recife, 2007. 56 f.

Dissertação (Mestrado em Zootecnia) Universidade Federal Rural de Pernambuco, Recife. 2007.

MDA. Censo Agropecuário 2006. Disponível em: <http://sistemas.mda.gov.br/ arquivos/2246122211.pdf>. Acesso em: $19 \mathrm{dez}$ 2012.

MENDES, C.G.; SAKAMOTO, S.M.; SILVA, J.B.A. et al. Análises físico-químicas e pesquisa de fraude no leite informal comercializado no Município de Mossoró, RN. Ciência Animal Brasileira, v.11, n.2, p.349-356, 2010.

MILLOGO, V.; SJAUNJA, K.S.;

QUÉADRAOGO, G.A. et al. Raw milk hygiene at farms, processing units and local markets in Burkina Faso. Food Control, v.21, p.10701074, 2010.

NERO, L.A.; MATTOS, M.R.; BELLOTI, V. et al. Leite cru de quatro regiões leiteiras brasileiras: perspectivas de atendimento dos requisitos microbiológicos estabelecidos pela instrução normativa 51. Ciência e Tecnologia de Alimentos, v.25, n.1, p.191-195, 2005.

PINTO, C.L.O.; MARTINS, M.L.; VANETTI, M.C.D. Qualidade microbiológica de leite cru refrigerado e isolamento de bactérias 
psicrotróficas proteolíticas. Ciência e

Tecnologia de Alimentos, v.26, n.3, 2006.

SALVESTRO, A.C.; JOSÉ, J.V.; GAVA, R. Caracterização do cenário da pecuária leiteira de Bom Sucesso. ENCONTRO INTERNACIONAL DE PRODUÇÃO

CIENTÍFICA CESUMAR, 6., 2009, Maringá. Anais eletrônicos... Maringá: CESUMAR. Disponível em: <http://www.cesumar.br/epcc2009/anais/alexan dre_castro_salvestro2.pdf>. Acesso em: 30 ago. 2010.

SANTOS, P.A.; SILVA, M.A.P.; SOUZA, C.M. et al. Efeito do tempo e da temperatura de refrigeração no desenvolvimento de microrganismos psicrotróficos em leite cru refrigerado coletado na macrorregião de Goiânia, GO. Ciência Animal Brasileira, v.10, n.4, p.1237-1245, 2009.

SILVA, L.C.C.; BELOTI, V.; TAMANINI, R. et al. Rastreamento de fontes da contaminação microbiológica do leite cru durante a ordenha em propriedades leiteiras do Agreste Pernambucano. Semina: Ciências Agrárias, v.32, n.1, p.267-276, 2011.

SILVA, V.A.; TEIXEIRA, S.R.; BERNARDO, W.F. Reflexões sobre sucessão e identidade entre produtores de leite que visitaram a Embrapa Gado de Leite. Fórum das Américas: Leite e Derivados - Congresso Internacional do Leite, 8., 2010, Juiz de Fora. Anais eletronicos... Juiz de Fora: Embrapa, 2010b. CD-ROM.

SOUSA, A.G.; NORONHA, J.F.; MOURA, C.J. et al. Influência da qualidade do leite sobre os custos de uma indústria de laticínios em Goiás. In: CONGRESSO DA SOCIEDADE

BRASILEIRA DE ECONOMIA, ADMINISTRAÇÃO E SOCIOLOGIA RURAL, 45., 2007, Londrina. Anais eletrônicos... Londrina: SOBER. Disponível em: $<$ http://www.sober.org.br/palestra/6/192.pdf>. Acesso em: 16 dez. 2012.

SOUTO, L.I.M.; SAKATA, S.T.; MINAGAWA, C.Y. et al. Qualidade higiênico-sanitária do leite cru produzido em propriedades leiteiras do Estado de São Paulo, Brasil. Veterinária e Zootecnia, v.16, n.3, p.491-499, 2009.

VIANA, K.F.; SETUBAL, B.F.; MENDES, V.A. et al. Comparação da contagem de células somáticas em leite cru por quatro métodos de coloração. Acta Veterinaria Brasilica, v.4, n.1, p.59-63, 2010. 